\title{
Optical, Structural, Morphological Properties of Chromium (III) Oxide Nanostructure Synthesized Using Spray Pyrolysis Technique
}

\author{
Fatin H. Mohammed ${ }^{\text {a* }}$ and Haitham M. Mikhlif ${ }^{b}$ \\ Department of Physics, College of Science, Mustansiriyah University, Baghdad, Iraq \\ bE-mail: haitham.mikhlif@uomustansiriyah.edu.iq \\ a*Corresponding author: fakt_2006@uomustansiriyah.edu.iq
}

\begin{abstract}
Nanostructure of chromium oxide $\left(\mathrm{Cr}_{2} \mathrm{O}_{3}-\mathrm{NPs}\right)$ with rhombohedral structure were successfully prepared by spray pyrolysis technique using Aqueous solution of Chromium (III) chloride $\mathrm{CrCl}_{3}$ as solution. The films were deposited on glass substrates heated to 450 ${ }^{\circ} \mathrm{C}$ using X-ray diffraction (XRD) shows the nature of polycrystalline samples. The calculated lattice constant value for the grown $\mathrm{Cr}_{2} \mathrm{O}_{3}$ nanostructures is $\mathrm{a}=\mathrm{b}=4.959 \AA \& \mathrm{c}=13.594 \AA$ and the average crystallize size (46.3-55.6) nm calculated from diffraction peaks, Spectral analysis revealed FTIR peak characteristic vibrations of Cr-O Extended and Two sharp peaks present at 630 and $578 \mathrm{~cm}^{-1}$ attributed to Cr-O "stretching modes", are clear evidence of the presence of crystalline $\mathrm{Cr}_{2} \mathrm{O}_{3}$. The energy band gap (3.4 eV) for the chromium oxide nanostructures was measured using the UV-VIS-NIR Optical Spectrophotometer. It was found that by scanning electron microscopy (SEM) and image results, there is a large amount of nanostructure with an average crystal size of 46.3-55.6 nm, which indicates that our synthesis process is a successful method for preparing $\mathrm{Cr}_{2} \mathrm{O}_{3}$ nanoparticles.
\end{abstract} Article Info.

\section{Introduction}

The study of microstructure and nanostructure has received increasing attention because of the new properties that materials may exhibit when reducing grain size [1]. Over the past decades, much progress has been made in the manufacture of nanostructure. "Nanomaterials", especially Transitional metal oxides have an important role in materials science, physics and chemistry as well as technological applications [2]. Metal oxides are commonly used in the manufacture of sensors, electronic circuits, fuel cells, and Coatings for corrosion-resistant surfaces and as a catalyst [3]. Nanostructure of metal oxides can have unique chemical properties due to their specific size and high density of edge surface locations [3,4]. Among the inorganic nanostructure, chromium nanostructure (III) $\left(\mathrm{Cr}_{2} \mathrm{O}_{3}\right)$ has got a lot of attention due to their wide applied fields, including pigment [5],"heterogeneous catalysts" [6,7]. Coating materials for the purpose of thermal protection [8,9], biological applications [10,11], digital recording system [12], photonic and electron ic devices $[13,14]$. Various techniques were developed for the assembly of $\mathrm{Cr}_{2} \mathrm{O}_{3}$ nanostructure such as hydrothermal [15], Solid pyrolysis [16], combustion [17], sol-gel [18], precipitation gelation [19], oxidation chromium [20], laser-induced deposition [21], mechanochemical reaction and subsequent heat Treatment [22], and "sonochemical methods" [23]. Many preparation methods, such as: sol-gel technology, "laser induced deposition", "hydrothermal reduction", chemical-mechanical reaction, "condensation-polymerization", "gas condensation", solid pyrolysis, homogeneous precipitation with the help of urea, microwave plasma,"sono-chemical reaction", thermal 
treatments, nano-casting method, hydrazine reduction and solution-combustion synthesis were used to prepare $\mathrm{Cr}_{2} \mathrm{O}_{3}$ nanostructures [24]. Most of these techniques are costeffective, complex, require high temperature, environmentally sensitive and special laboratory equipment. Therefore, for the current study, a typical hydrothermal method was used to synthesize $\mathrm{Cr}_{2} \mathrm{O}_{3}$ nanostructures due to the fact that this preparation method reduces cost and is straightforward at low temperature.

In this paper a simple and important method for the synthesis of nanosized $\mathrm{Cr}_{2} \mathrm{O}_{3}$ chromium oxide by spray pyrolysis technique in nano is described. The surface properties, size, morphology and crystallographic structure of $\mathrm{Cr}_{2} \mathrm{O}_{3}$ particles are characterized by means of X-ray diffraction (XRD), and scanning electron microscope (SEM) which will give much valuable information about these materials. In addition, optical properties of chromium (III) oxide $\left(\mathrm{Cr}_{2} \mathrm{O}_{3}\right)$ nanostructure which determined using the UV-VIS-NIR Optical Spectrophotometer.

\section{Experimental work}

An aqueous solution of Chromium (III) chloride $\mathrm{CrCl}_{3}$ (Sigma-Aldrich Labor) was prepared by dissolving $0.15 \mathrm{M}$ of "chromium chloride" in $100 \mathrm{ml}$ in "distilled water" with constant moving for 45 minutes. In order to keep the $\mathrm{pH}$ value of the solution at 10, we added a few drops of "ammonium hydroxide" to the solution while moving. Chromium (III) chloride react with water to produce hydrogen chloride and chromium (III) oxide using compressed air as a carrier gas [25].

$$
2 \mathrm{CrCl}_{3}+3 \mathrm{H} 2 \mathrm{O}\left[\text { temp] }=6 \mathrm{HCl}+\mathrm{Cr}_{2} \mathrm{O}_{3}\right.
$$

The precursor solution was transformed into an aerosol by an ultrasonic nebulizer operating at a frequency of $1.7 \mathrm{MHz}$, which is connected to the precipitation chamber via a spray nozzle where the precipitation process takes place inside the chamber on a glass substrate at a temperature of $(450 \pm 5)^{\circ} \mathrm{C}$, it has been maintained, the nozzle-substrate distance at $7 \mathrm{~cm}$ where the spraying continues for five minutes.

In this part of the experiment, thin films of chromium oxide were prepared use the aerosol generated in the ultrasonic nebulizer was injected into the stainless-steel chamber through a nozzle as shown in Fig.1with deposition time $(5 \mathrm{~min})$ to get required layer of $\mathrm{Cr}_{2} \mathrm{O}_{3}$ thin film. The film prepared from $\mathrm{Cr}_{2} \mathrm{O}_{3}$ was green in color and had good adhesion to glass substrates as it was tested by visual inspection.

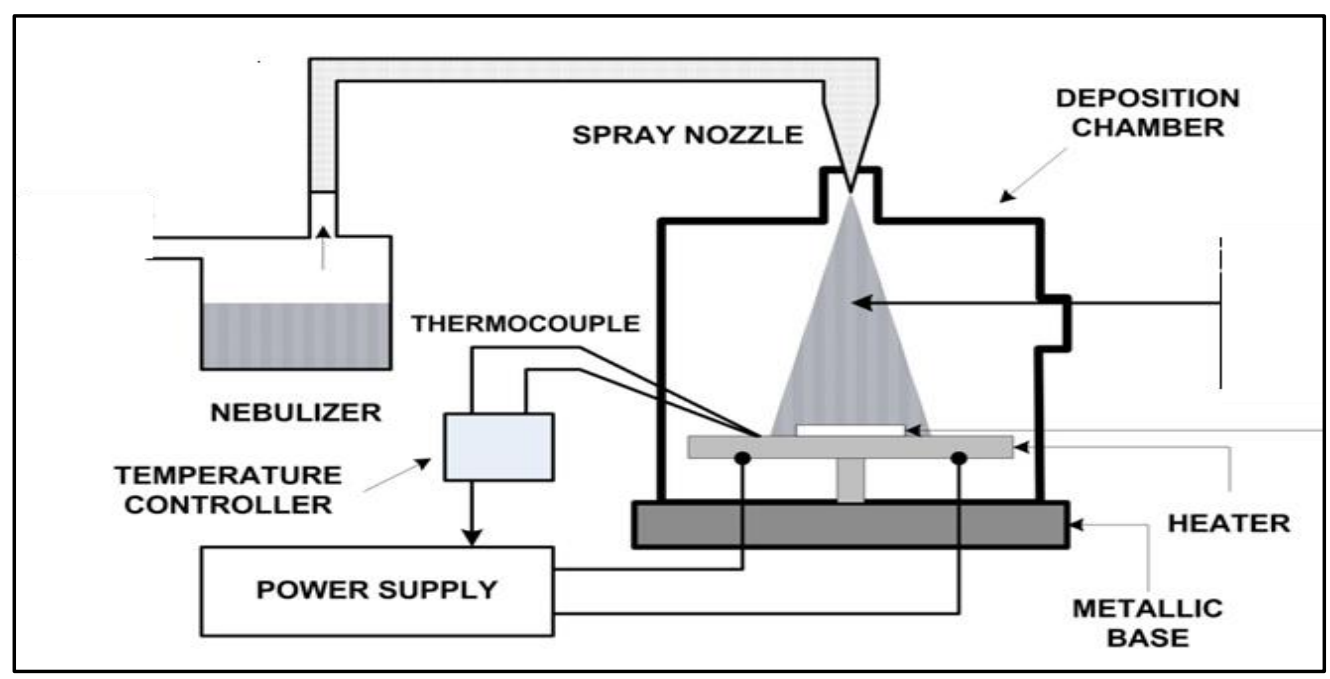

Figure 1: Schematic diagram for system set up. 


\section{Results and discussion}

\subsection{X-Ray and FTIR studies}

The X-ray diffraction was carried out on "a Philips Analytical XPERT". Using a diffractometer " $\mathrm{Cu} \mathrm{K} \alpha$ radiation $(\lambda=1.54056 \AA)$ with a "MINIPROP detector", It works at $40 \mathrm{Kv}$ and $30 \mathrm{~mA}$. It was recorded X-ray diffraction patterns between $2 \theta=10^{\circ}$ to $80^{\circ}$. shows the XRD pattern (Fig. 2), it can be observed peaks that belong to the crystalline phases of $\mathrm{Cr}_{2} \mathrm{O}_{3}$ (012), (104), (110), (113), (024), (116) and (300). All peaks can be set to $\mathrm{Cr}_{2} \mathrm{O}_{3}$ stage according to data released by the "ICDD (International Center for Diffraction Data) cards", No. card (00-038-1479). The average crystallite sizes were calculated using the Scherrer equation $\mathrm{D}=\mathrm{K} \lambda /(\beta \cos \theta)$ where, $\lambda=1.54056 \AA$ is the wavelength of an $\mathrm{X}$-ray, $\mathrm{K}=0.9$ is the "Scherer constant" $\beta$ is (FWHM) and " $\theta$ " is the "Bragg diffraction angle". The calculated lattice constant value for the grown $\mathrm{Cr}_{2} \mathrm{O}_{3}$ nanostructures is $\mathrm{a}=\mathrm{b}=4.959$ $\AA$ \& $c=13.594 \AA$ whereas reported [26]value for lattice constant is $a=b=4.953 \AA$ \& $\mathrm{c}=13.578 \AA$. The recorded and calculated values of the lattice constants agree well. Table (1) shows the size of the grains for the prepared sample, which is agreed with the report [27].

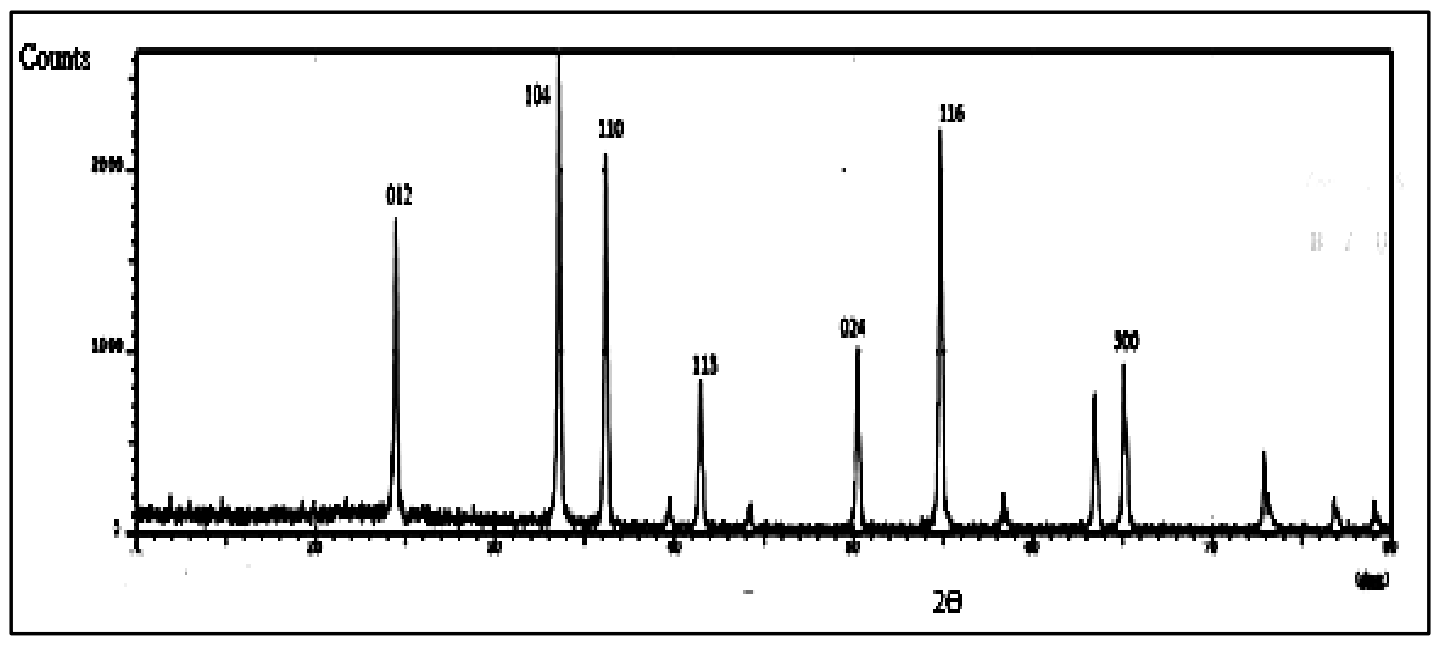

Figure 2: $\mathrm{XRD}$ model of $\mathrm{Cr}_{2} \mathrm{O}_{3}$ nanostructure prepared by spray pyrolysis.

Table 1: Experimental and standard values of peaks, and grain size of $\mathrm{Cr}_{2} \mathrm{O}_{3}$ sample prepared with SP technique.

\begin{tabular}{|c|c|c|c|c|c|}
\hline $2 \theta$ (deg) & $\begin{array}{c}d h k l(\operatorname{Exp} .) \\
(\AA) \\
(\AA)\end{array}$ & $\begin{array}{c}\text { dhkl (Std.) } \\
(\stackrel{A}{A})\end{array}$ & $h k l$ & $\begin{array}{c}F W H M \\
(\operatorname{deg})\end{array}$ & $G . S(n m)$ \\
\hline 24.5055 & 3.62965 & 3.63132 & 012 & 0.167 & 46.354 \\
\hline 33.5954 & 2.6656 & 2.66533 & 104 & 0.1651 & 47.958 \\
\hline 36.1976 & 2.47959 & 2.4796 & 110 & 0.1575 & 51.524 \\
\hline 41.4719 & 2.17561 & 2.1752 & 113 & 0.6950 & 50.4 \\
\hline 50.2167 & 1.81533 & 1.81521 & 024 & 0.1609 & 49.677 \\
\hline 55.2476 & 1.66133 & 1.67237 & 116 & 0.1433 & 55.662 \\
\hline 65.0980 & 1.43173 & 1.43157 & 300 & 0.1738 & 46.354 \\
\hline
\end{tabular}

Figure 3 shows the "Fourier-transform infrared" (FTIR) spectra of chromium oxide $\left(\mathrm{Cr}_{2} \mathrm{O}_{3}\right)$ sample prepared by SP technique. As it can be observed, at a frequency of 3420 $\mathrm{cm}^{-1}$, where the broad band, it compatible with the "stretching modes" of $\mathrm{OH}$ groups. Generally, $\mathrm{Cr}_{2} \mathrm{O}_{3}$ absorption bands appear below $1000 \mathrm{~cm}^{-1}$ due to "inter-atomic vibrations". Two sharp peaks present at 630 and $578 \mathrm{~cm}^{-1}$ attributed to $\mathrm{Cr}-\mathrm{O}$ "stretching modes", are clear evidence of the presence of crystalline $\mathrm{Cr}_{2} \mathrm{O}_{3}$ [28]. 


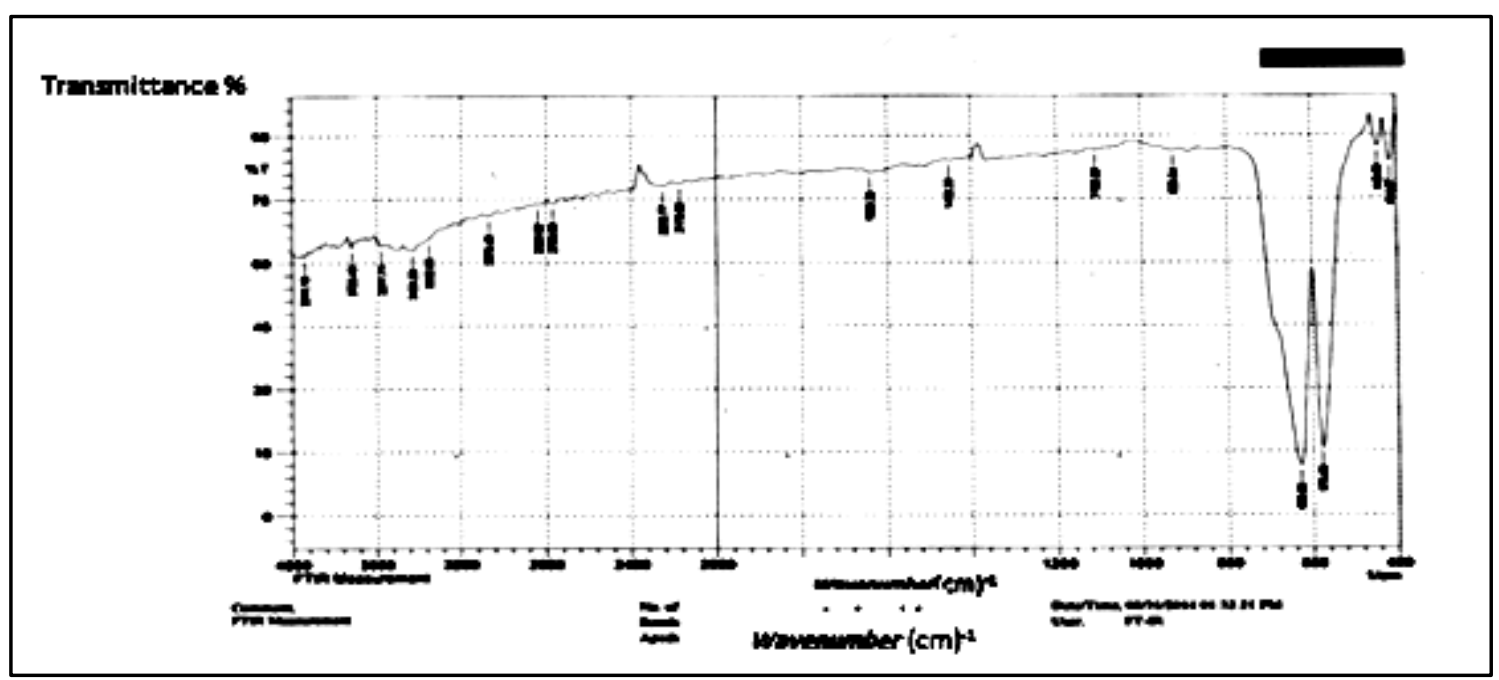

Figure 3: FTIR spectrum of the nano-sizedCr2O3 prepared by SP technique.

\subsection{Morphological analysis}

The morphology of $\mathrm{Cr}_{2} \mathrm{O}_{3}$ nanostructure prepared with SEM images was distinguished as shown in Fig. 4. From the images results, it can be noticed that a large amount of nanostructure (NPs) with an average crystallite size of 46.3-55.6 nm, which indicates that our synthesis process is a successful method to prepare $\mathrm{Cr}_{2} \mathrm{O}_{3}$ nanoparticle.

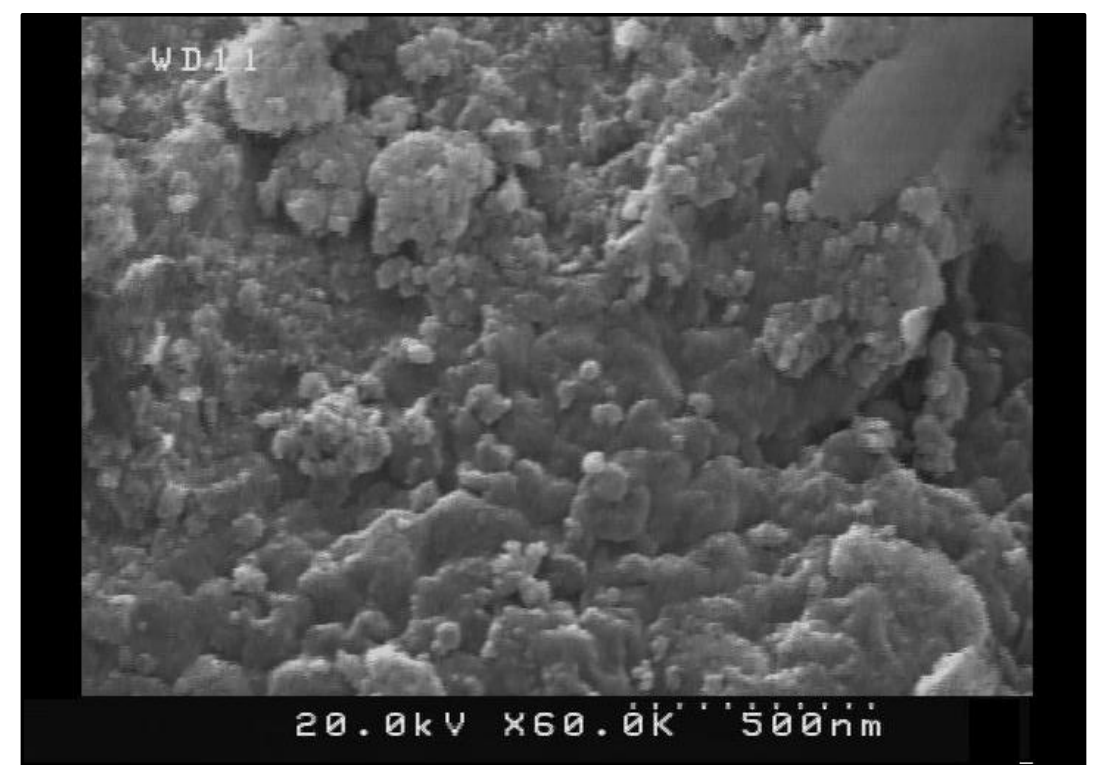

Figure 4: SEM image of Cr2O3 sample obtained at precursor concentration of $0.15 M$ by SP.

\subsection{Optical analysis}

Figure 5 shows the "optical absorption spectrum" of the Synthesized $\mathrm{Cr}_{2} \mathrm{O}_{3}$ nanostructure. The spectrum shows the generic direction of absorption, i.e., reduced absorption of material with a decrease in the frequency of incident radiation. Figure 6, shows the alteration of $(h v \alpha)^{2}$ with photon energy (hv) for the synthesized $\mathrm{Cr}_{2} \mathrm{O}_{3}$ thin film of thickness $170 \mathrm{~nm}$, the film thickness was measured by a thin film measuring system (Stellar Net Inc. Thin Film measurement systems), which works on the principle of spectroscopy. The plot shows the direct band gap of $\sim 3.4 \mathrm{eV}$, which is agreed with the report [29]. 


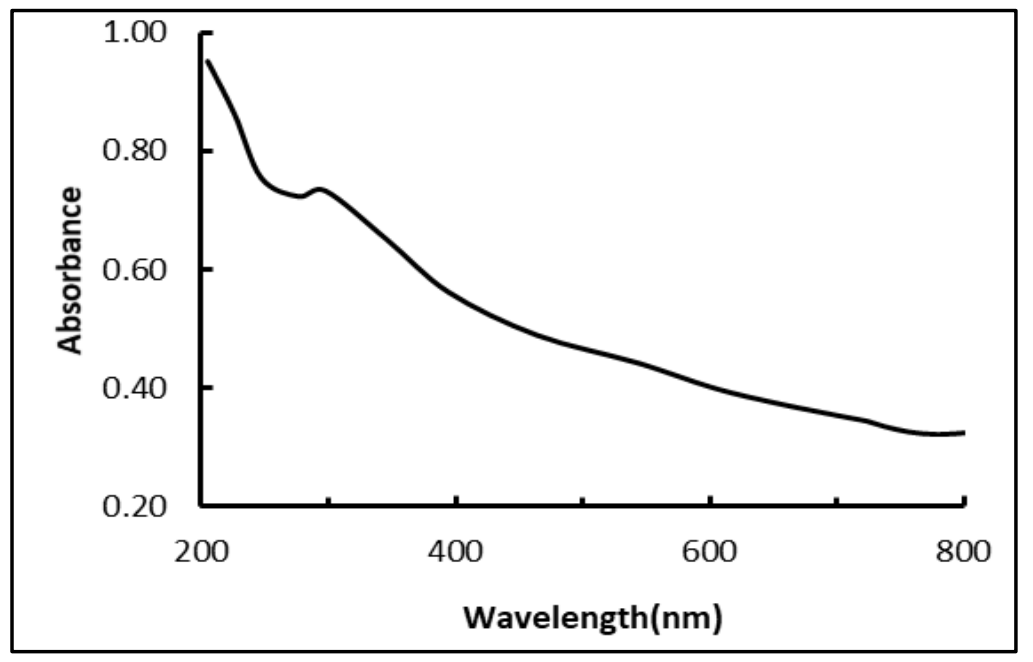

Figure 5: UV-VIS-NIR spectrum typical for Cr2O3 thin film prepared by SP technique.

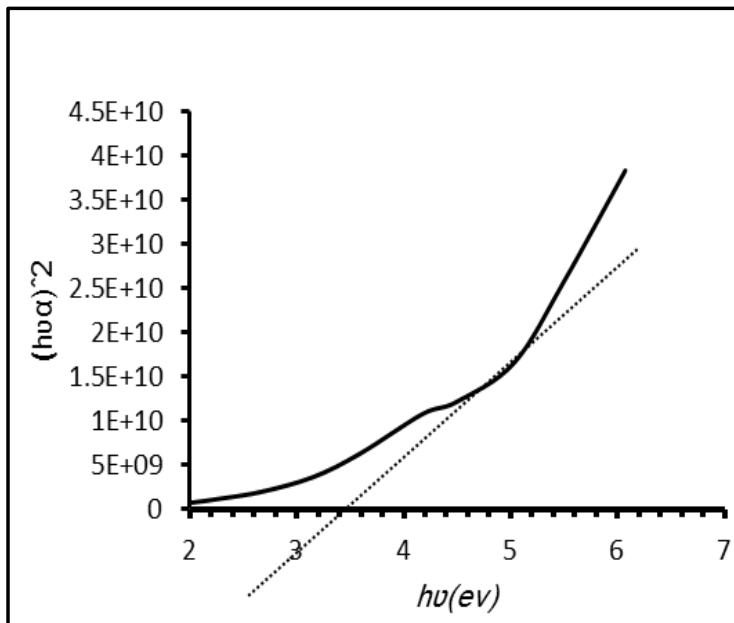

Figure 6: Variations of (ahv) ${ }^{2}$ with photon energy (hv) for $\mathrm{Cr}_{2} \mathrm{O}_{3}$ thin film of thickness $170 \mathrm{~nm}$.

\section{Conclusions}

Using spray pyrolysis technology, a thin film of chromium oxide nanostructure was fabricated using simple chromium chloride materials as primers. The results were obtained by XRD, FTIR, SEM, and UV-VIS. spectrometers. Identical and specific crystal phase $\left(\mathrm{Cr}_{2} \mathrm{O}_{3}\right)$, bonding $(\mathrm{Cr}-\mathrm{O})$, purity $(\mathrm{Cr}, \mathrm{O})$ and energy bandgap $(3.4 \mathrm{eV})$ of $\mathrm{Cr}_{2} \mathrm{O}_{3}$ nanostructures. The average crystallizes size (46.3-55.6) $\mathrm{nm}$ calculated from diffraction peaks indicating the formation of a nanostructured layer.

\section{Acknowledgements}

We would like to show our gratitude to department of physics (laser and molecular group) in Baghdad university to allow us to use their lab to accomplish this work.

\section{Conflict of interest}

We certify that we have NO affiliations with or involvement in any organization or entity with any financial interest. 


\section{References}

1. Khan I., Saeed Kh., Nanoparticlres: properties, applications and toxicities. Arabian Journal of chemistry, 2019. 12(7): pp. 908-931.

2. Gesheva K., Ivanova T., Bodurov G., Szilagyi I. M., Justh N., Technologies for deposition of transition metal oxide thin films: application as functional layers in "smart windows" and photocatalytic systems. Journal of physics 2016. conference series 682.

3. Fernandez-Garcia M., Martinez-Arias A., Hanson J. C. and J. A. Rodriguez, Nanostructured Oxides in Chemistry Characterization and properties, Chemical Reviews, 2004. 104(9): pp. 4063-4104.

4. Oun A. A., Shankar Sh. and Rhim J., Multifunctional nanocellulose/metal and metal oxide nanoparticle hybrid nanomaterials. Critical Reviews in Food Science and Nutrition 2019. 60(3), 435-460.

5. Hebbar D., Choudhari K. S., Shivashankar S. A., Santhosh C., Kulkarni S. D., Facile microwave-assisted synthesis of $\mathrm{Cr}_{2} \mathrm{O}_{3}$ nanostructure with high near-infrared reflection for roof-top cooling applications. Journal of Alloys and compounds, 2019. 785: pp. 747-753.

6. Karimiana R., Pirib F., Synthesis and Investigation the Catalytic Behavior of $\mathrm{Cr}_{2} \mathrm{O}_{3}$ Nanoparticles. JNS, 2013. 3: pp. 87-92.

7. Wang G., Zhang L., Deng J., Dai H., He H., Au Ch. Tong, Preparation, characterization, and catalytic activity of chromia supported on SBA-15 for the oxidative dehydrogenation of isobutene. Applied Catalysis A: General, 2009. 355(12); pp. 192-201.

8. Chang T., Cao X., Li N., Long S., Gao X., Dedon L. R., Sun G., Luo H. and Jin P., Facile and Low-Temperature Fabrication of Thermochromic $\mathrm{Cr}_{2} \mathrm{O}_{3} / \mathrm{NO}_{2}$ Smart Coatings: Enhanced Solar Modulation Ability, High Luminous Transmittance and $U V$-Shielding Function. ACS Appl. Mater. Interfaces. 2017. 9(31): pp. 26029-26037.

9. Singh Sh. P., Chinde S., Kamal S. S., Rahman M. F., Mahboob M., Grover P., Genotoxic effects of chromium oxide nanoparticles and microparticles in Wistar rats after 28 days of repeated oral exposure. ESPR, 2015. 23: pp. 3914-3924.

10. Hassan D., Talhakhlil A., Solangi A. R., El-Mallul A., Shinwari Z. Kh., Maaza M., Physiochemical properties and novel biological applications of Callistemon viminalis-mediated $\alpha-\mathrm{Cr}_{2} \mathrm{O}_{3}$ nanoparticles. Applied Organometallic Chemistry, 2019. 33(8).

11. Lu M., Cui Y., Zhao S., Fakhri A., $\mathrm{Cr}_{2} \mathrm{O}_{3} /$ cellulose hybrid nanocomposites with unique properties: Facile synthesis, photocatalytic, bactericidal and antioxidant application. Journal of Photochemistry and Photobiology B: Biology, 2020. 205.

12. Bijker M. D., Bastiaens J. J. J., Draaisma E. A., de Jong L. A. M., Sourty E., Saied S. O. Sullivan J. L., The development of a thin $\mathrm{Cr}_{2} \mathrm{O}_{3}$ wear protective coating for the advanced digital recording system. Tribology International, 2003. 36(4-6); pp. 227233.

13. He X., Antonelli D., Synthesen und Anwendungen von übergangsmetallhaltigen mesoporösen Molekularsieben. Angew. Chem. Int. Ed, 2002.114(2): pp. 222-238.

14. He X., Antonelli D., Recent Advances in Synthesis and Applications of Transition Metal Containing Mesoporous Molecular Sieves. Angew Chem. Int. Ed, 2002. 41(2); pp. 214-229.

15. Hebbar D., Choudhari K. S., Shivashankar S. A., Santhosh C., Kulkarni S. D., Facile microwave-assisted synthesis of $\mathrm{Cr}_{2} \mathrm{O}_{3}$ nanoparticles with high near-infrared reflection for roof-top cooling applications. Journal of Alloys and compounds, 2019. 785: pp. 747-753. 
16. Mohanapandian K. and Krishnan A., Synthesis, Structural, Morphological and Optical Properties of $\mathrm{Cu}^{2+}$ Doped $\mathrm{Cr}_{2} \mathrm{O}_{3}$ Nanoparticles. International Journal of Advanced Engineering Technology, 2016. VII(II): pp. 273-279.

17. Wang H., Han W., Li X., Liu B., Tang H., Li Y., Solution Combustion Synthesis of $\mathrm{Cr}_{2} \mathrm{O}_{3}$ Nanoparticles and the Catalytic Performance for Dehydrofluorination of 1,1,1,3,3-Pentafluoropropane to 1,3,3,3-Tetrafluoropropene Molecules, 2019. 24(2): pp. 361.

18. Sangwan P., Kumar H., Synthesis, Characterization and Antibacterial Activities of Chromium Oxide Nanoparticles Against Klebsiella Pneumoniae. Asian Journal of Pharmaceutical and Clinical Research, 2017. 10(2): pp. 206-209.

19. Abdullah H. I. \& Abbas L. J., Photosynthesis of Chromium Oxide Nanoparticles from Chromium Complexes. Ijapbcr, 2017. 7(1): pp. 1-8.

20. Tian S., Ye X., Dong Y., Li W., Zhang B., Li B., Feng H., Production and Characterization of Chromium Oxide $\left(\mathrm{Cr}_{2} \mathrm{O}_{3}\right)$ via a Facile Combination of Electrooxidation and Calcination. International Journal of Electrochemical Science, 2019. 14: pp. 8805-8818.

21. Karimian R., Piri F., Synthesis and Investigation the Catalytic Behavior of $\mathrm{Cr}_{2} \mathrm{O}_{3}$ Nanoparticles. JNS, 2013. 3: pp. 87-92.

22. Tsuzuki T., Mc Cormick P. G., Synthesis of $\mathrm{Cr}_{2} \mathrm{O}_{3}$ Nanoparticles by mechanochemical processing. Acta Materialia. 2000. 48(11): pp. 2795-2801.

23. Alrehaily L. M., Joseph J. M. and Wren J. C., Radiation-Induced Formation of Chromium Oxide Nanoparticles: Role of Radical Scavengers on the Redox Kinetics and Particle Size. J. Phys. Chem. C 2015.119(28): pp. 16321-16330.

24. Abdullah M. M., Rajab Fahd M. and Al-Abbas Saleh M., Structural and optical characterization of $\mathrm{Cr}_{2} \mathrm{O}_{3}$ nanostructures: Evaluation of its dielectric properties. AIP Advances, 2014. 4, 027121.

25. Rer, characterization of $\mathrm{Cr}_{2} \mathrm{O}_{3}$ catalysts for $\mathrm{Cl} / \mathrm{F}$ exchange reaction. M.Sc. thesis, chemical Engineer, 2004. Humboldt University.

26. Al-sharuee I.F. and Mohammed F.H. Investigation study the ability of superhydrophobic silica to adsorb the Iraqi crude oil leaked in water. IOP Conference Series: Materials Science and Engineering, 2019, 571(1): pp. 1-6.

27. Jamal A., Raahman M. M., Khan Sh. B., Abdullah M. M., Faisaal M., Asiri A. M., Aslam A., Khan P. and Akhtar K., Simple Growth and Characterization of $\alpha-\mathrm{Sb}_{2} \mathrm{O}_{4}$ : Evaluation of their Photo-catalytic and Chemical Sensing Applications. J. Chem. Soc. Pak, 2013. 35(3): pp. 570 -576.

28. Sone B. T., Manikandan E., Gurib-Fakim A. and Maaza M., Single-phase $\alpha-\mathrm{Cr}_{2} \mathrm{O}_{3}$ nanostructure' green synthesis using Callistemon viminalis' red flower extrac, Green Chemistry Letters and Reviews, 2016. 9(2): pp. 85-90.

29. Julkarnain M., Hossain J., Sharif K. S. and Khan K. A., Optical properties of thermally evaporated $\mathrm{Cr}_{2} \mathrm{O}_{3}$ thin films. Canadian Journal on Chemical Engineering \& Technology, 2012. 3(4): pp. 81-85. 


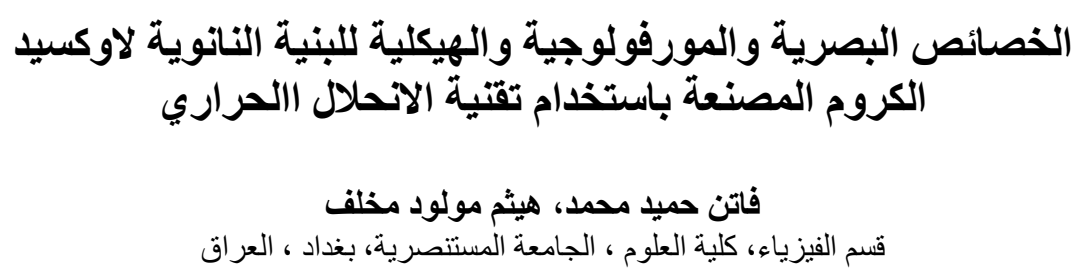

الخلاصة

تم تحضير الهيكل النانوي لأكسيد الكروم (Cr2 $)$ ذات البنية المعينية بواسطة تقنية الانحلال الحر اري بالرش باستخدام محلول مائي من كلوريد الكروم (XRD

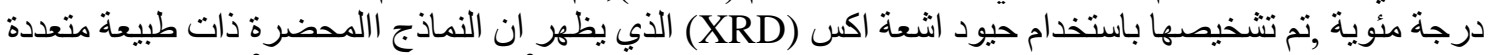
a = b = التبلور قيمة ثابت الثبكة المحسوبة للبنى النانوية Cr

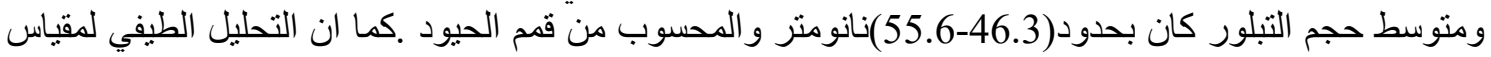

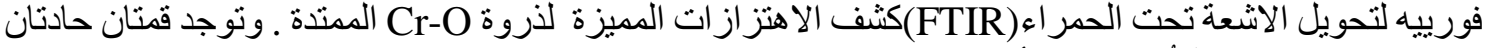

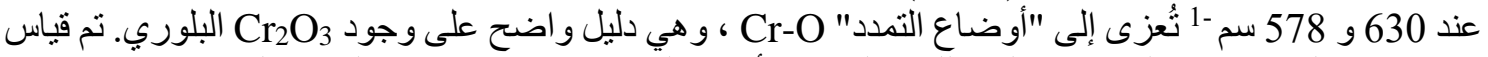

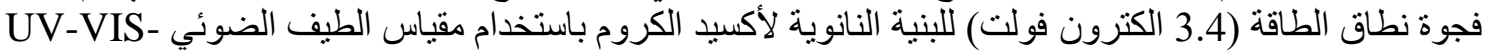

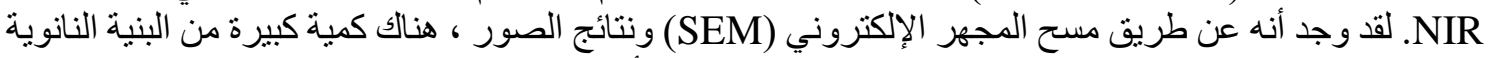

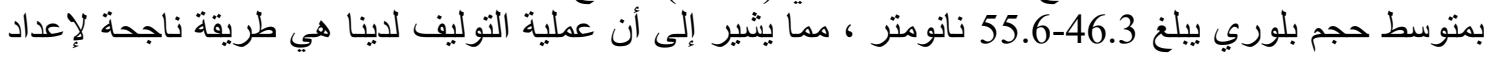

الجسيمات النانوية 